\title{
The monitoring of bovine pregnancies derived from transfer of in vitro produced embryos
}

\author{
Marcel A.M. TAVerne ${ }^{\mathrm{a} *}$, Simone P. Breukelman ${ }^{\mathrm{a}}$, Zsolt Perényi ${ }^{\mathrm{b}}$, \\ Steph J. Dieleman ${ }^{\mathrm{a}}$, Peter L.A.M. VOS ${ }^{\mathrm{a}}$, Herman H. JONKER ${ }^{\mathrm{a}}$, \\ Lisette DE RUIGH ${ }^{\mathrm{c}}$, Jannecke M. VAN WAGTENDONK-DE LEEUW ${ }^{\mathrm{c}}$, \\ Jean-François BECKERS ${ }^{b}$ \\ ${ }^{a}$ Department of Farm Animal Health, Faculty of Veterinary Medicine, \\ Utrecht University, The Netherlands \\ ${ }^{b}$ Department of Physiology of Reproduction, Faculty of Veterinary Medicine, \\ University of Liège, Belgium \\ ${ }^{c}$ Holland Genetics, R\&D, Arnhem, The Netherlands
}

\begin{abstract}
Both an increased rate of embryonic, foetal and perinatal losses, and the occurrence of deviations in foetal and placental development are associated with bovine pregnancies obtained from in vitro produced embryos. This thus requires for a more accurate and frequent monitoring of foetal and maternal functions during pregnancies. Such approaches will enable to establish the period during which these losses and deviations in development occur and to plan possible clinical interventions. This paper reviews some recent data on return rates, late embryonic and foetal losses in recipients after the transfer of either MOET, IVF or nuclear transfer embryos. Special attention is paid to the diagnostic value of measurements of pregnancy specific/associated proteins and progesterone in maternal plasma. Possibilities to measure foetal body sizes, size of placentomes and foetal heart rate by means of transrectal or transabdominal ultrasonography are illustrated with data from the literature and with recent results from our own large field study with MOET, IVP-co-culture and IVP-SOF embryos.
\end{abstract}

cow / pregnancy / pregnancy proteins / ultrasonography / foetus / placenta / foetal heart rate / embryo transfer / in vitro fertilization / nuclear transfer

\footnotetext{
* Correspondence and reprints
}

E-mail: m.a.m.taverne@vet.uu.nl 


\section{INTRODUCTION}

In cattle breeding, the interest of collecting data on the course of a pregnancy in individual females generally subsides, once a positive pregnancy diagnosis has been made within two months after mating or artificial insemination. The same is true for the pregnancies obtained after embryo transfer, despite the fact that considerable efforts and costs have sometimes to be made to reach a pregnancy in the first place. Attention to pregnant females is only resumed at the time of calving, when it needs to be judged if delivery can take place spontaneously or should be accomplished by artificial means to improve the chances for survival of the calf. Observations and data connecting (pathophysiological) events during (early) pregnancy and parturition with the morbidity and performance of calves at later life are not routinely available. However, such an approach appears to be more relevant keeping in mind the recently pronounced concept $[1-3,45]$ that several diseases encountered during adult life might have their origin during the period of foetal development. The same might be true for physical performance and (re)production in domestic species [37, 39, 40, 48]. In this respect one seems to have forgotten that, within the context of research on growth and production of farm animals, Grahm Everitt already warned in 1968 that "The extent to which events of later life may be modified by factors operating during the formative stages appears insufficiently appreciated"(see Bell [4]). The so-called "Large Calf Syndrome" [7, 24, 64] might be an undesirable example of such types of long-term effects.

Early reports on increased embryonic and foetal losses and the variable occurrence of deviant foetal development during pregnancies obtained from in vitro produced embryos (reviewed by Kruip en den Daas [35]), have stimulated the interest for research on the prenatal development of farm animal species, especially in ruminants.
Besides many (ongoing) studies to unravel the cellular and molecular mechanisms of deviant development of IVF-derived and cloned embryos [11, 41, 53, 64], several authors have reported on placental and foetal growth and pathophysiological events during the perinatal period $[18,19,22,26,29$, $30,47,49,51,59,60]$. The bovine foetus and placenta are not easily accessible for (on farm) investigations, especially during the second and third trimester of gestation. Yet, there is a need for more intensive monitoring of pregnancies, not only to collect more accurate information on the exact timing of prenatal losses, but also to document or predict deviations in prenatal development. Such approaches will contribute to the understanding of the mechanism of disturbed development and will allow timely clinical interventions, either during pregnancy or at parturition. This contribution will therefore concentrate on late embryonic, foetal and perinatal losses resulting from pregnancies derived from transfers of IVF-derived and cloned embryos, with a special focus on methods by which such pregnancies can be more intensively monitored. Our own data from a field study of our own group, in which we compared the course and outcome of IVP and MOET pregnancies, will be presented as well.

\section{THE EMBRYONIC AND EARLY FOETAL PERIOD}

\subsection{Pregnancies after transfer of IVP-embryos}

When recipients show a regular return to oestrus (between 19 and 22 days after their first oestrus), it can be assumed that early embryonic mortality occurred, i.e. before maternal recognition of pregnancy took place. Both after A.I. and embryo transfer of in vivo or in vitro produced embryos, high rates of such early embryonic losses have been reported [17, 25, 38, 46, 54], especially when quality grade 2 embryos had been used 
for transfer. Recently, Heyman et al. [26] concluded on the basis of plasma progesterone levels, that on day 21 , no significant differences in the percentages of presumed pregnancies existed between groups of recipients to which either cloned or IVF embryos had been transplanted.

Immediately after this period during which regular returns can be expected, the presence of a pregnancy can be presumed (on the basis of plasma progesterone profiles or irregular returns) or diagnosed for the first time (by means of ultrasonography or measurements of plasma pregnancy proteins). When a positive early pregnancy diagnosis is followed by a return to oestrus between days 23 and 42, late embryonic mortality has occurred. Under field conditions, however, the first pregnancy diagnosis usually takes place only during the foetal period (around day 40). This means that it is usually very difficult to derive accurate figures on early and late embryonic mortality from published data on pregnancy rates. In their world-wide retrospective review on the results from transfers of IVP embryos, Kruip and den Daas [35] reported that while $70 \%$ of the embryonic losses after A.I. or ET occurred within the first 21 days of fertilization, this was only $58 \%$ for IVP embryos. This might be associated with a more strict selection of good quality IVP blastocysts. A more detailed picture can be obtained from the data published by van Wagtendonk et al. (2000). These authors compared return rates and pregnancy outcome after (single) transfers of either a MOET, IVP-co-culture or IVP-SOF embryo (Tab. I).

Total return rates were not significantly different between the three groups, but the return rate between 0 and 31 days was higher in the recipients with a MOET or IVP-SOF embryo. However, the relative proportion of returns between days 24 and 31 was significantly higher in the IVP-coculture group, while losses beyond day 52 were also higher in this group (although not significantly different). In a recent paper [36] pregnancy losses occurring between days 38 and 90 were found to be $11.2 \%$ and $9.9 \%$ for lactating dairy cows, inseminated after spontaneous or synchronized oestrus respectively.

In a recent field study, we monitored groups of recipients with similar types of embryos (for details of production: see van Wagtendonk-de Leeuw et al. [60]) by regular blood sampling between day 7 and day 119 after embryo transfer. Around day 35 , transrectal ultrasonography took place for pregnancy diagnosis and in 65 of these recipients ultrasonography was repeated at weekly intervals for foetometry and measurements of foetal heart rate (see below). The data are presented in Table II.

Failure of pregnancy without an observed return to oestrus occurred in $3.2 \%, 4.4 \%$ and $4.5 \%$ of the recipients of the MOET, IVP co-culture and IVP-SOF group, respectively.

Although the percentage of pregnancy failures was slightly higher in the IVP-SOF

Table I. Returns to oestrus after transfer of a single MOET, IVP-co-culture or IVP-SOF embryo to recipients of the herd of Holland Genetics (after van Wagtendonk-de Leeuw et al. [60]).

\begin{tabular}{lccc}
\hline & $\begin{array}{c}\text { MOET } \\
(n=465)\end{array}$ & $\begin{array}{c}\text { IVP-co-culture } \\
(n=157)\end{array}$ & $\begin{array}{c}\text { IVP-SOF } \\
(n=101)\end{array}$ \\
\hline Total return (\%) & 54.4 & 51.5 & 46.1 \\
Returns between days 0-31 as \% of total returns & 80.6 & $68.2^{*}$ & 80.9 \\
Returns between days 24-31 as \% of day 0-31 returns & 17.2 & $31.0^{*}$ & 13.2 \\
Returns between days 32-52 as \% of total returns & 13.1 & 20.0 & 10.6 \\
Returns beyond day 52 as \% of total returns & 6.3 & 11.8 & 8.5 \\
\hline
\end{tabular}


Table II. Early and late returns to oestrus of recipients to which either a MOET, IVP-co-culture or IVP-SOF embryo had been transferred (Perényi et al., in preparation).

\begin{tabular}{|c|c|c|c|}
\hline & $\begin{array}{c}\text { MOET } \\
(n=118)\end{array}$ & $\begin{array}{l}\text { IVP-co-culture } \\
\quad(n=44)\end{array}$ & $\begin{array}{l}\text { IVP-SOF } \\
(n=106)\end{array}$ \\
\hline Total \% pregnancy failures & 52.5 & 52.3 & 63.2 \\
\hline Returns before day 24 as a $\%$ of total pregnancy failures & 54.8 & 56.5 & 58.2 \\
\hline $\begin{array}{l}\text { Returns between days } 24 \text { and } 119 \text { as a } \% \text { of total } \\
\text { pregnancy failures }\end{array}$ & 35.5 & 30.4 & 37.3 \\
\hline Returns beyond day 119 as a $\%$ of total pregnancy failures & 6.5 & 8.7 & 0 \\
\hline
\end{tabular}

group and no late foetal losses occurred in these recipients, there were no differences between the three groups as to the relative proportions of early embryonic losses (before day 24) and late embryonic plus early foetal losses (between days 24 and 119). Overall, about one third of all transfers failed before day 24 , while slightly more than one fifth of the transfers resulted in losses between days 24 and 119.

On the basis of plasma progesterone (P4: see Dieleman and Bevers [15]) and PAG1 (see Zoli et al. [65]) profiles of these animals, we were able to analyse the pregnancy failures between day 24 and 119 in more detail. By using plasma levels from ongoing pregnancies with calvings at term as reference values, decreases of P4 and PAG1 levels below one tailed $95 \%$ confidence intervals resulted in the attribution of each case of pregnancy failure with a complete data file $(n=56)$ to one of the following three groups:

A: recipients in which a drop or subnormal concentration occurred earlier in the $\mathrm{P} 4$ than in the PAG1 profile.

$\mathrm{B}$ : recipients in which a drop or subnormal concentration occurred earlier in the PAG than in the P4 profile.

$\mathrm{C}$ : recipients in which subnormal hormone concentrations or decreases occurred at (about) the same time.

Typical examples of plasma profiles from recipients of group A and B are presented in Figures $1 \mathrm{~A}$ and $1 \mathrm{~B}$.
Table III presents the distribution of these three types of pregnancy failures, occurring between day 24 and 119, over the three groups of recipients.

These data indicate that (a) type A was the dominant type of failure in each group of recipients, and (b) type B losses occurred slightly more frequent in recipients with IVP-SOF embryos. If one accepts that PAG1 profiles reflect the viability of the trophoblast/placenta [55, 56], this would implicate that in pregnancies which have already passed the stage of maternal recognition of pregnancy, failures after transfer of IVP-SOF embryos are more often the result of disturbed conceptus development. In this respect it is interesting to note that impaired vascularization of the allantois has been more often associated with conceptuses derived from in vitro produced ruminant embryos [14, 28, 44].

We were not able to detect significant differences in plasma P4 and PAG1 levels between the three groups of recipients during the first 4 months of ongoing pregnancies [62], but we did not find differences between the mean birth weights of calves from these three groups. Yet, an increased foetal weight [17] and increased placental weight $[5,17]$ have already been reported during midgestation in the recipients of IVP embryos. It appears that the dramatically increased plasma levels of PAG during the final weeks of gestation are better correlated with foetal weight [51] than the 
levels during early pregnancy. However, it remains to be investigated to what extent the reduced number of placentomes, with a much larger individual size, (which have been found in IVP pregnancies by Bertolini and Anderson [5, 6]), do affect plasma PAG levels. Compared to placentas from foetuses derived from in vivo embryos, the relative

(A)

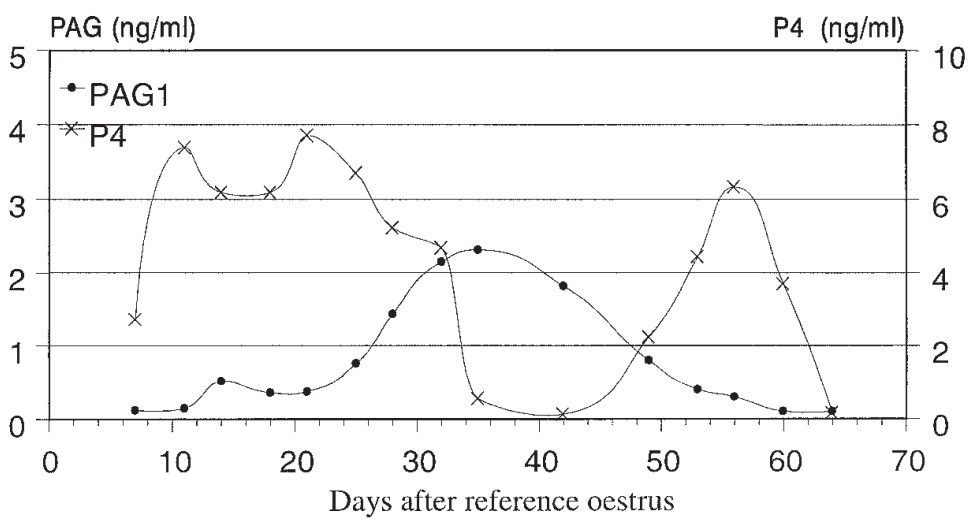

(B)

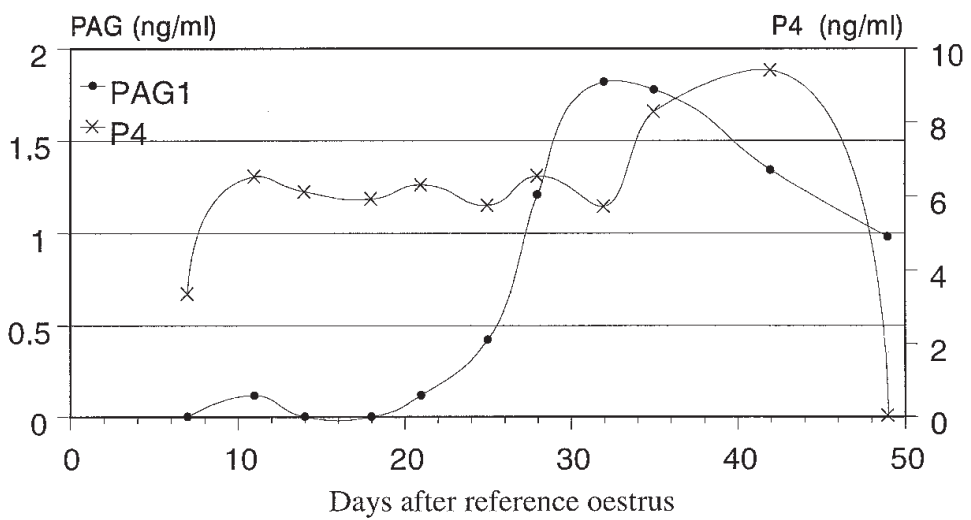

Figure 1. Plasma progesterone (P4) and PAG1 levels in two cases with an early pregnancy loss. (A) a recipient, pregnant after transfer of a MOET embryo but returning to oestrus on day 42 after the reference oestrus; a decline of plasma P4 precedes a decrease in PAG1 levels; (B) a recipient, pregnant after transfer of a IVP-SOF embryo but returning to oestrus on day 49 after reference oestrus; a decline in the PAG1 level precedes the drop in P4 [43].

Table III. Distribution of three types of pregnancy losses among the three categories of recipients which returned to oestrus between days 24 and 119 .

\begin{tabular}{lccr}
\hline & $\begin{array}{c}\text { MOET } \\
(n=22)\end{array}$ & $\begin{array}{c}\text { IVP-co-culture } \\
(n=7)\end{array}$ & $\begin{array}{c}\text { IVP-SOF } \\
(n=25)\end{array}$ \\
\hline Type A pregnancy loss $(n=36)$ & $17(77 \%)$ & $5(71 \%)$ & $14(56 \%)$ \\
Type B pregnancy loss $(n=16)$ & $5(23 \%)$ & $1(14.5 \%)$ & $8(32 \%)$ \\
Type C pregnancy loss $(n=4)$ & 0 & $1(14.5 \%)$ & $3(12 \%)$ \\
\hline
\end{tabular}


abundance of binucleate cells, by which the pregnancy proteins are produced, have been found in the placentas from in vitro embryos on day 63 [20], although the same authors previously reported a lower volume density of binucleate cells in the placentas of IVP foetuses at day 222 [18]. There is clearly a need for more detailed studies on the possible relationships between gross morphology (number and size of placentomes), vascularization, cellular differentiation and production of proteins and hormones of the bovine placenta during normal A.I., MOET and IVP pregnancies (see also below).

It has been described $[8,12]$ that transrectal ultrasonography can be used to visualize the details of the bovine conceptus at very early stages (before day 24). However, reliable quantification of ultrasonographic details of the development of the conceptus is only possible at a later stage $[6,13$, $23,33]$. Especially the measurement of foetal body structures (CRL: crown rump length; BPD: biparietal diameter of the cranium; CAU: cross section of the abdomen) can be expected to reflect both the retardation or enhancement of foetal growth. Recently, Bertolini and coworkers [6] reported that the CRL of foetuses, derived from IVP-co-culture beef cattle embryos, had a significantly reduced CRL between days 37-58 when compared to foetuses from MOET embryos, while at birth the mean body weight of the IVP calves $(n=6)$ was significantly higher.

Because it has frequently been reported that pregnancies derived from IVP embryos suffer from a higher incidence of both prenatal losses and result more often in heavy foetuses and offspring, we also performed repeated ultrasonographic measurements of foetuses. Between days 35 and 119 foetal growth was compared between pregnancies resulting from the transfer of MOET, IVP-coculture and IVP-SOF embryos. Reports from early pregnancies in women suggest that deviations from normal foetal heart rate (FHR) may be predictive for future foetal losses or for foetuses with chromosomal abnormalities [50, 57]. Reports on abnormal vascularization of the allantois during early pregnancy $[14,44]$ and data on deviant cardiac structure and function in some foetal and newborn ruminants resulting from IVP embryos [27, 52, 60] require more studies on prenatal cardiovascular function. This is supported by the recent finding of Bertolini et al. [6] that FHR of IVP-concepti $(n=6)$ was significantly higher between days 37 and 93 of gestation when compared with MOET $(n=6)$ foetuses. We therefore also included measurements of FHR in our study with three groups of bovine pregnancies $[9,10]$. At weekly intervals, transrectal scans were video-taped and measurements of BPD, CAU (at the insertion of the umbilical cord) and CRL and calculations of FHR were performed afterwards. It appeared that repeated and reliable measurements of CRL of the same foetus were less often possible during transrectal scanning than with the other two types of foetometry. In addition, the measurement of the CRL appeared less reliable in our hands, because bending of the foetal spine by foetal movements appeared to cause a considerable variation of the CRL during a single scanning session. FHR data are presented in Figure 2.

We found no significant differences in BPD, CAU and FHR between the three groups of foetuses between days 35-110 of pregnancy. However, the mean birth weights of calves resulting from these three different types of embryos were not significantly different either. Also when BPD, CAU and FHR were retrospectively compared between calves with a birth weight below $40 \mathrm{~kg}$ and those weighing more than $51 \mathrm{~kg}$, no significant differences in these foetal parameters were found.

Changes in FHR followed a parabolic curve, different from the initial data published by Curran et al. [13], but comparable to the curve that was based on a limited group of A.I. foetuses by Ginther [23]. Plots 
FHR

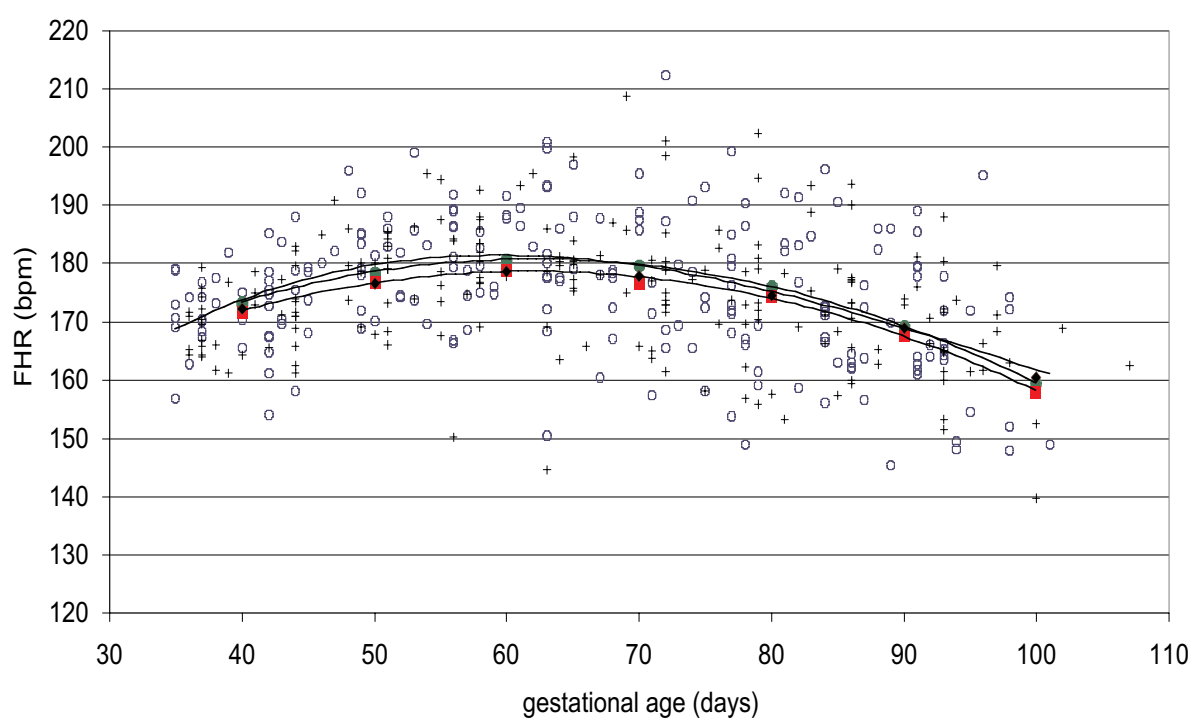

Figure 2. Plots of individual (open symbols) calculated Fetal Heart Rates and LS-means (closed symbols and with lines of best fit) for three groups of foetuses; circles: MOET foetuses $(n=25)$; squares: IVP-co-culture foetuses $(n=14)$; rhombs: IVP-SOF foetuses $(n=22)$ [9].

of trend lines for FHR of our individual foetuses demonstrated that in some of the pregnancies that did not proceed until term, FHR was outside the $95 \%$ confidence intervals. This indicates that it might be useful to further explore FHR, based on more frequently performed measurements, as an early indicator of future foetal death in cattle.

\subsection{Pregnancies after transfer of cloned embryos}

Because embryonic and foetal losses are considerably higher and abnormal foetal development and increased birth weight occur more often in pregnancies after the transfer of cloned embryos [35, 47, 63], it appears even more appropriate to use intensive ultrasonographic and biochemical monitoring in recipients of cloned embryos. Ectors et al. [16] demonstrated that PAG levels in heifers pregnant from transferred nuclear transfer embryos were higher during late pregnancy than in recipients of IVF embryos. In a recent paper from France [26] monitoring took place during pregnancies obtained after transfer of cloned (somatic adult, somatic foetal or embryonic) and IVF-co-culture embryos. As already indicated above, early embryonic losses did not appear to be increased after the transfer of cloned embryos, as judged by plasma progesterone levels on day 21. However, at the time of the first and the second transrectal ultrasound scan, significantly less recipients with somatic clones appeared pregnant. Data on the percentage of pregnant animals at different stages of the first trimester and the final calving rates are summarized in Table IV.

Foetal survival decreased dramatically, especially in the recipients who received an embryo cloned from adult somatic cells. Foetal deaths were not observed beyond day 90 in recipients of the control IVF or embryonic cloned groups. 
Table IV. Data on pregnancies of recipients to which either a cloned embryo (3 different types) or an IVF-co-culture embryo had been transferred (after Heymann et al. [26]).

\begin{tabular}{lcccc}
\hline & $\begin{array}{c}\text { Embryos } \\
\text { cloned from } \\
\text { somatic adult } \\
\text { cells }(n=133)\end{array}$ & $\begin{array}{c}\text { Embryos } \\
\text { cloned from } \\
\text { somatic foetal } \\
\text { cells }(n=40)\end{array}$ & $\begin{array}{c}\text { Embryos } \\
\text { cloned from } \\
\text { embryonic } \\
\text { cells }(n=67)\end{array}$ & $\begin{array}{c}\text { Control } \\
\text { IVF-co-cult } \\
\text { embryos } \\
(n=51)\end{array}$ \\
\hline \% presumed pregnant D21 & 55.6 & 57.5 & 62.6 & 62.7 \\
\% found pregnant D35 & 33.8 & 27.5 & 49.2 & 52.9 \\
\% found pregnant D50 & 27.1 & 22.5 & 41.8 & 50.9 \\
\% found pregnant D70 & 14.3 & 22.5 & 37.3 & 49.0 \\
\% found pregnant D90 & 12.0 & 22.5 & 34.3 & 47.0 \\
\% calves at term & 6.8 & 15.0 & 34.3 & $49.0^{*}$ \\
\hline
\end{tabular}

* Including one twin from a single embryo transfer.

Similar to our own findings on PAG1 levels during ongoing pregnancies of IVP and MOET, no significant differences in plasma PSP60 levels were found between the 4 groups of pregnancies that produced live, full term calves. Interestingly, plasma PSP60 levels on day 50 in recipients with somatic clones that lost their conceptus between days 50 and 90 were already significantly higher than in recipients with surviving somatic and subsequently nonsurviving embryonic clones. This would mean that the trophoblast of somatic clones is more likely to demonstrate aberrant early cellular differentiation, leading to increased numbers of binucleate cells. It remains to be investigated if this is directly associated with a less developed early vascularization resulting in subsequent placental insufficiency and foetal death. At later stages (days 150, 180 and 210), the recipients of somatic clones which had developed a severe hydroallantois, also had significantly elevated PSP60 levels as compared to nonpathological pregnancies of the control or cloned groups. Compared with the IVF controls, an increased size of the placentomes (ultrasonographically measured at 2 week intervals) was found in the recipients with somatic clones, but this was not reflected in altered foetal functions like counted FHR and growth of the diameter of the foetal aorta.

\section{THE LATE FOETAL PERIOD}

Direct monitoring of foetal functions is very difficult during the second half of gestation in cattle. Due to the large size of the foetus, its variable intra-abdominal position and the limited penetration depth of ultrasound transducers, access to foetal body structures is rather limited, especially during the final three months of gestation. This means that growth curves based on ultrasonographic measurements of foetal structures usually finish around the end of the second trimester (for details see: Kähn [33]; Ginther [23]). Although the measurements of the diameter of the foetal eye can be used to estimate foetal age, there is no evidence as to whether this parameter accurately reflects the differences in foetal growth. So, conclusions on the deviations of foetal growth during later stages of development have to be based on either transversal observations of collected foetuses or on measurements in newborns. Under farm conditions, prenatal identification of abnormal intrauterine development is more likely indicated by the recognition (by external features, transrectal examination and ultrasound observation) of recipients with hydroallantois, a pathology which has been reported more often in cows pregnant from IVP embryos [26, 35]. Additional monitoring of the course of pregnancy and placental and foetal well-being has to 
rely on the measurements of proteins (different PAG's, PSPB's) and hormones (progesterone, conjugated and unconjugated oestrogens, prostaglandin metabolites, cortisol, placental lactogen) in maternal plasma [34], although their value for the prediction of abnormal foetal development or foetal distress needs further exploration.

Prenatal, ultrasound-guided puncture of foetal fluids has been applied during early stages of bovine pregnancies [21, 61], but reports on fluid aspiration during late gestation are not available and might be judged to be too risky. Under experimental conditions a surgical method (installing catheters in the foetal umbilical vessels) has been used to investigate the differences between IVP and A.I. control foetuses with respect to blood chemistry and hormone levels during the final days before delivery [49]. While IVP foetuses had an elevated haemoglobin (and as a consequence a higher oxygen content) and lower lactate levels compared to arterial samples of A.I. foetuses, there were no differences between the two groups in arterial oxygen saturation, foetal glucose tolerance, blood cortisol levels and the response to ACTH. In fact none of the observed differences pointed to a poor preparation of IVP foetuses to extrauterine life, in contrast to the clinical findings reported earlier for several newborn cloned calves by Garry et al. [22]. Because both an increased limb length [30] and a high incidence of flexural deformities of the limbs [22] have been observed in newborn calves derived from in vitro produced embryos, it appears very relevant to explore foetal motility [23] during IVP pregnancies. Prenatal restriction of articular mobility is associated with flexural abnormalities in the cow [58] and disturbed foetal mobility around calving could contribute (through abnormal foetal posture and/or position) to the higher rates of dystocia reported for IVP calvings. Also prolonged measurements of foetal heart rate (FHR), preferably combined with registration of gross foetal movements, might be useful in this respect, because different FHR patterns have been associated with different so-called behavioral states, both in human and animal foetuses (for reviews see: Nijhuis [42]). Significant differences in characteristics of FHR between acidotic and non-acidotic calves have been found during calving [31] and continuous, transcutaneous Doppler measurements of prenatal FHR appear feasible in the cow [32]. Preliminary data show no differences in late gestational FHR characteristics between healthy A.I. and IVP foetuses [9], but the value of such measurements for the prediction of prenatal distress still needs to be assessed in cattle.

\section{SUMMARIZING CONCLUSIONS}

While pregnancies obtained from transplantation of in vitro produced embryos suffer from increased (though variable) rates of embryonic, foetal and perinatal losses and developmental disturbances, it appears rather difficult, especially under farm conditions, to identify conceptuses with deviations in development at an early stage. Transversal studies, collecting conceptuses at different stages of gestation, have demonstrated that significant differences of foetal and placentome weight and size may occur rather early in gestation, but non-invasive longitudinal ultrasonographic foetometry and counting of FHR did not reveal significant differences between ongoing pregnancies of MOET and IVP embryos during the first 4 months. Determinations of maternal plasma levels of placenta-derived pregnancy proteins seem to be more valuable for a timely detection of abnormal development. For pregnancy losses between days 24 and 119 , a decrease of pregnancy associated protein levels, preceding luteal regression, occurred slightly more often in IVP than in MOET recipients of the same herd. This indicates that pregnancy failures after transfer of IVP embryos are more often the result of a failure of conceptus development. On the contrary, abnormally elevated levels of 
these proteins around day 50 were found to precede foetal losses in pregnancies from somatic clones, pointing to a disturbance of placental cellular differentiation. Because the uterine contents are more difficult within reach, direct measurements of foetal and placental growth during the last trimester of gestation are restricted. Besides a close and regular clinical inspection of the dams and blood sampling for the monitoring of hormones and pregnancy proteins, transabdominal studies of foetal movements and FHR might improve the prenatal diagnosis of aberrant foetal life in cows.

\section{REFERENCES}

[1] Barker D.J.P., Outcome of low birthweight, Horm. Res. 42 (1994) 223-230.

[2] Barker D.J.P., In utero programing of cardiovascular disease, Theriogenology 53 (2000) 555-574.

[3] Barker D.J.P., Clark Ph.M., Fetal undernutrition and disease in later life, Rev. Reprod. 2 (1997) 105-112.

[4] Bell A.W., Foetal growth and its influence on postnatal growth and development, in: Boorman K.N., Buttery P.J., Lindsay D.B. (Eds.), The Control of Fat and Lean Deposition, Butterworth/Heinemann, 1992, pp. 11-127.

[5] Bertolini M., Anderson G.B., The placenta as a contributor to production of large calves, Theriogenology 57 (2000) 181-187.

[6] Bertolini M., Mason J.B., Beam S.W., Carneiro G.F., Sween M.L., Kominek D.J., Moyer A.L., Famula T.R., Sainz R.D., Anderson G.B., Morphology and morphometry of in vivo- and in vitro-produced bovine concepti from early pregnancy to term and association with high birth weights, Theriogenology 58 (2000) 973-994.

[7] Boerjan M.L., den Daas J.H.G., Dieleman S.J Embryonic origins of health: long term effects of IVF in human and livestock, Theriogenology 53 (2000) 537-547.

[8] Boyd J.S., Orman S.N., Ayliffe T.R., Use of a high frequency transducer with real time B-mode ultrasound scanning to identify early pregnancy in cows, Vet. Rec. 123 (1988) 8-11.

[9] Breukelman S.P., The Large Offspring Syndrome. Can it be detected during bovine pregnancy? MSc-thesis Faculty of Veterinary Sci ences, Utrecht University, The Netherlands, 2000.

[10] Breukelman S.P., Reinders J.M.C., Jonker F.H., De Ruigh L., Kaal L.M.T.E., Van Wagtendonkde Leeuw A.M., Taverne M.A.M., Early fetometry and fetal heart rates in bovine pregnancies resulting from transfers of either IVP coculture, IVP-SOF, or MOET embryos, Theriogenology 55 (2001) 324

[11] Cross J.C., Genes regulating embryonic and fetal survival, Theriogenology 55 (2001) 193-207.

[12] Curran S., Pierson R.A., Ginther O.J., Ultrasonographic appearance of the bovine conceptus from days 10 through 20, J. Am. Vet. Med. Assoc. 189 (1986) 1289-1294.

[13] Curran S., Pierson R.A., Ginther O.J., Ultrasonographic appearance of the bovine conceptus from days 20 through 60, J. Am. Vet. Med. Assoc. 189 (1986) 1295-1302.

[14] De Sousa P.A., King T., Harkness L., Young L.E., Walker S.K., Wilmut I., Evaluation of gestational deficiencies in cloned sheep fetuses and placentae, Biol. Reprod. 65 (2001) 23-30.

[15] Dieleman S.J., Bevers M.M., Effects of monoclonal antibodies against PMSG administered shortly after the preovulatory LH surge on time and number of ovulations in PMSG/PG-treated cows, J. Reprod. Fertil. 81 (1987) 533-542.

[16] Ectors F.J., Schmidt M., Sulon J., Delval A., Remy B., Avery B., Beckers J.F., BPAG profiles in recipient heifers after transfer of IVF and nuclear transfer embryos, Theriogenology 45 (1996) 283.

[17] Farin P.W., Farin C.E., Transfer of bovine embryos produced in vivo or in vitro: survival and fetal development, Biol. Reprod. 52 (1995) 676-682.

[18] Farin P.W., Stockburger E.M., Rodriguez K.F., Crosier A.E., Blondin P., Alexander J.E., Farin C.E., Placental morphology is altered following transfer of bovine embryos produced in vitro, Theriogenology 53 (2000) 474.

[19] Farin P.W., Crosier A.E., Farin C.E., Influence of in vitro systems on embryo survival and fetal development in cattle, Theriogenology 55 (2001) 151-170.

[20] Farin P.W., Stewart R.E., Rodriguez K.F., Blondin P., Alexander J.E., Farin C.E., Morphometry of bovine placentas at 63 days following transfer of embryos produced in vivo or in vitro, Theriogenology 55 (2001) 320 .

[21] Garcia A, Salaheddine M., Bovine ultrasoundguided transvaginal amniocentesis, Theriogenology 47 (1997) 1003-1008.

[22] Garry F.B., Adams R., McCann J.P., Odde K.G., Postnatal characteristics of calves produced by nuclear transfer cloning, Theriogenology 45 (1996) 141-152.

[23] Ginther O.J., Ultrasonic Imaging and Animal Reproduction: Cattle (book 3), Equiservices Publishing, Cross Plains, Wisconsin, USA, 1998.

[24] Greve T., Jacobson H., New embryo-technologies: implications for animal health and welfare, Arch. Anim. Breed. 44 (2001) 80-90. 
[25] Hasler J.F., Hendersson W.B., Hurtgen P.J., Jin Z.Q., McCauley A.D., Mower S.A., Neely B., Shuey L.S., Stokes J.E., Trimmer S.A., Production, freezing and transfer of IVF embryos and subsequent calving results, Theriogenology 43 (1995) 141-152.

[26] Heymann Y., Chavatte-Palmer P., LeBourhis D., Camous S., Vignon X., Renard J.P., Frequency and occurrence of late-gestation losses from cattle cloned embryos, Biol. Reprod. 66 (2002) 6-13.

[27] Hill J.R., Roussel A.J., Cibelli J.B., Edwards J.F., Hooper N.L., Miller M.W., Thompson J.A., Looney C.R., Westhusin M.E., Robl J.M., Stice S.L., Clinical and pathological features of cloned transgenic calves and fetuses (13 case studies), Theriogenology 51 (1999) 1451-1465.

[28] Hill J.R., Burghardt R.C., Jones K., Long C.R., Looney C.R., Shin T., Spencer T.E., Thompson J.A., Winger Q.A., Westhusin M.E., Evidence for placental abnormality as the major cause of mortality in first-trimester somatic cell cloned bovine fetuses, Biol. Reprod. 63 (2000) 1787-1794.

[29] Jacobson H., Schmidt M., Holm P., Sangild P.T. Greve T., Callesen H., Ease of calving, blood chemistry, insulin and bovine growth hormone of newborn calves derived from embryos produced in vitro in culture systems with serum and co-culture or with PVA, Theriogenology 54 (2000) 147-158

[30] Jacobson H., Schmidt M., Holm P., Sangild P.T., Vajta G., Greve T., Callesen H., Body dimensions and birth and organ weights of calves derived from in vitro produced embryos cultured with or without serum and oviduct epithelium cells, Theriogenology 53 (2000) 1761-1769.

[31] Jonker F.H., van Geijn H.P., Chan W.W., Rausch W.-D., van der Weijden G.C., Taverne M.A.M., Characteristics of fetal heart rate changes during the expulsive stage of bovine parturition in relation to fetal outcome, Am. J. Vet. Res. 57 (1996) 1373-1381.

[32] Jonker F.H., van Oord H.A., Mulder E.J.H., Taverne M.A.M., Continuous Doppler fetal heart rate monitoring in the near term bovine fetus: comparison of 30 and 60 min computer evaluated records, Proceedings Annual Meeting Society for Theriogenology, Baltimore, Maryland, 1998, pp. 160-161.

[33] KähnW., Veterinary Reproductive Ultrasonography, Schlütersche, Hannover, Germany and Mosby-Wolfe, London, England, 1994.

[34] Kindahl H., Kornmatitsuk B., Königsson K., Gustafsson H., Endocrine changes in late bovine pregnancy with special emphasis on fetal wellbeing, Domest. Anim. Endocrinol. 23 (2002) 321-328.

[35] Kruip Th.A.M., den Daas J.H.G., In vitro produced and cloned embryos: effects on pregnancy, parturition and offspring, Theriogenology 47 (1997) 43-52.
[36] Lopez-Gatius F., Santolaria P., Yániz J., Rutllant J., López-Béjar M., Factors affecting pregnancy loss from gestation Day 38 to 90 in lactating dairy cows from a single herd, Theriogenology 57 (2002) 1251-1261.

[37] Maltin C.A., Delday M.I., Sinclair K.D., Steven J., Sneddon A.A., Impact of manipulations of myogenesis in utero on the performance of adult skeletal muscle, Reproduction 122 (2001) 359-374.

[38] Markette K.L., Seidel G.E., Elsden R.P., Estimations of embryonic losses in bovine embryo transfer recipients from progesterone profiles and returns to estrus, Theriogenology 23 (1985) 45-62.

[39] Maxfield E.K., Sinclair K.D., Dunne L.D., Broadbent P.J., Robinson J.J., Stewart E., Kyle D.G., Maltin C.A.S., Temporary exposure of ovine embryos to an advanced uterine environment does not affect fetal weight but alters fetal muscle development, Biol. Reprod. 59 (1998) 321-325.

[40] Maxfield E.K., Sinclair K.D., Dunne L.D., Broadbent P.J., McEvoy T.G., Robinson J.J., Maltin C.AS., Short-term culture of ovine embryos modifies fetal myogenesis, Am. J. Physiol. 274 (Endocrinol. Metab. 37) (1998) E1121-E1123.

[41] Niemann H., Wrenzycki C., Alterations of expression of developmentally important genes in preimplantation bovine embryos by in vitro culture conditions: implications for subsequent development, Theriogenology 53 (2000) 21-34

[42] Nijhuis J.G., Fetal behaviour. Developmental and perinatal aspects, Oxford University Press, 1992.

[43] Perényi Z., Investigations on pregnancyassociated glycoproteins in the cow, Ph.D. thesis Faculty of Veterinary Medicine, University of Liège, Belgium, 2002.

[44] Peterson A.J., McMillan W.H., Thompson J.G., Various allantoic pathologies are associated with malformation of allantoic development of the IVP bovine embryo, Proceedings 14th ICAR, Stockholm, Sweden, 2000, p. 159.

[45] Ravelli A.C.J., van de Meulen J.H.P., Michels R.P.J., Osmond C., Barker D.J.P., Hales C.N., Bleker O.P., Glucose tolerance in adults after prenatal exposure to famine, Lancet 351 (1998) 173-177.

[46] Reichenbach H.D., Liebrich J., Berg U., Brem G., Pregnancy rates and births after unilateral or bilateral transfer of bovine embryos produced in vitro, J. Reprod. Fertil. 95 (1992) 363-370.

[47] Renard J.P., Zhou Q., LeBourhis D., ChavattePalmer P., Hue I., Heymann Y., Vignon X., Nuclear transfer technologies: between successes and doubts, Theriogenology 57 (2002) 203-222.

[48] Rhind S.M., Rae M.T., Brooks A.N., Effects of nutrition and environmental factors on the fetal programming of the reproductive axis, Reproduction 122 (2001) 205-214. 
[49] Sangild P.T., Schmidt M., Jacobson H., Fowden A.L., Forhead A., Avery B., Greve T., Blood chemistry, nutrient metabolism, and organ weights in fetal and newborn calves derived from in vitro-produced bovine embryos, Biol Reprod. 62 (2000) 1495-1504.

[50] Schats R., Jansen C.A.M., Wladimiroff J.W. Embryonic heart activity: appearance and development in early human pregnancy, Br. J. Obstet. Gynaecol. 97 (1990) 989-994.

[51] Schmidt M., Greve T., Avery B., Beckers J.F., Sulon J., Hansen H.B., Pregnancies, calves and calf viability of in vitro produced bovine embryos, Theriogenology 46 (1996) 527-539.

[52] Sinclair K.D., McEvoy T.G., Maxfield E.K. Maltin C.A., Young L.E., Wilmut I., Broadbent P.J., Robinson J.J., Aberrant fetal growth and development after in vitro culture of sheep zygotes, J. Reprod. Fertil. 116 (1999) 177-186.

[53] Sinclair K.D., Young L.E., Wilmut I., McEvoy T.G., In utero overgrowth in ruminants following embryo culture: lessons from mice and a warning to men, Hum. Reprod. 15 Suppl. 5 (2000) 68-86.

[54] Stubbings R.B., Walton J.S., Relationship between plasma progesterone concentrations and pregnancy rates in cattle receiving either fresh or previously frozen embryos, Theriogenology 26 (1986) 145-155.

[55] Szenci O., Taverne M.A.M., Beckers J.F., Sulon J., Varga L., Börzsönyi L., Hanzen C., Schekk G., Evaluation of false ultrasonographic diagnoses in cows by measuring plasma levels of bovine pregnancy-associated glycoprotein 1 , Vet. Rec. 142 (1998) 304-306.

[56] Szenci O., Humblot P., Beckers J.F., Sasser G., Sulon J., Baltusen R., Varga J., Bajcsy C.A. Taverne M.A.M., Plasma profiles of progesterone and conceptus proteins in cows with spontaneous embryonic / foetal mortality as diagnosed by ultrasonography, Vet. J. 159 (2000) 287-290

[57] Tannirandom Y., Manataya S., Uerpairojkit B., Tanawattanacharoen S., Wacharaprechanont T., Charoenvidhya D., Reference intervals for first trimester embryonic / fetal heart rate in a Thai population, J. Obstet. Gynaecol. Res. 26 (2000) 367-372.

[58] Van Huffel X., Clinical and experimental contribution to the pathogenesis of congenital articular rigidity in the calf in Belgium, $\mathrm{Ph} . \mathrm{D}$, thesis Faculty of Veterinary Medicine, Ghent University, Belgium, 1990.

[59] Van Wagtendonk-de Leeuw A.M., Aerts B.J.G., den Daas J.H.G., Abnormal offspring following in vitro production of bovine preimplantation embryos, a field study, Theriogenology 49 (1998) 883-894.

[60] Van Wagtendonk-de Leeuw A.M., Mullaart E. de Roos A.P.W., Merton J.S., den Daas J.H.G. Kemp B., de Ruigh L., Effects of different reproduction techniques: A.I., MOET or IVP, on health and welfare of bovine offspring, Theriogenology 53 (2000) 575-597.

[61] Vos P.L.A.M., Pieterse M.C., van der Weijden G.C., Taverne M.A.M., Bovine fetal fluid collection: transvaginal, ultrasound-guided puncture technique, Vet. Rec. 127 (1990) 502-504

[62] Vos P.L.A.M., Perényi Z., Jonker F.H., de Ruigh L., van Wagtendonk A.M., Breukelman S., Soede N.M., Taverne M.A.M., Beckers J.F., Dieleman S.J., Plasma concentrations of bovine pregnancy-associated glycoprotein during ongoing pregnancies after transfer of in vitro-produced bovine embryos, Theriogenology 55 (2001) 328.

[63] Wilson J.M., Williams J.D., Bondioli K.R., Looney C.R., Weshusin M.E., McCalla D.F. Comparison of birth weight and growth characteristics of bovine calves produced by nuclear transfer (cloning), embryo transfer and natural mating, Anim. Reprod. Sci. 38 (1995) 73-83.

[64] Young L.E., Sinclair K.D., Wilmut I., Large offspring syndrome in cattle and sheep, Rev. Reprod. 3 (1998) 155-163.

[65] Zoli A.P., Guilbault C.A., Delahaut P., BenitzOrtiz W., Beckers J.F., Radioimmunoassay of a bovine pregnancy-associated glycoprotein in serum: its application for pregnancy diagnosis, Biol. Reprod. 46 (1992) 82-92.

To access this journal online: www.edpsciences.org 